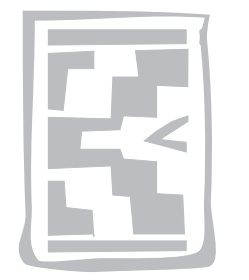

\title{
Preliminary survey of ticks (Acari: Ixodidae) on cattle in northern Sudan
}

\author{
D.A. SALIH ${ }^{1 *}$, S.M. HASSAN², A.M. EL HUSSEIN¹ and F. JONGEJAN ${ }^{3}$
}

\begin{abstract}
SALIH, D.A., HASSAN, S.M., EL HUSSEIN, A.M. \& JONGEJAN, F. 2004. Preliminary survey of ticks (Acari: Ixodidae) on cattle in northern Sudan. Onderstepoort Journal of Veterinary Research, 71: 319-326

In a cross sectional survey conducted during the period June 2001 to July 2002, the geographical distribution of ticks on cattle in the Sudan was determined. Seventeen locations were surveyed from Northern, Central, Eastern, Western, Blue Nile and White Nile Provinces. Total body collections of ticks were made from 20 cattle at each location. Four tick genera and 11 species were identified. The tick species collected included Amblyomma lepidum, Amblyomma variegatum, Boophilus decoloratus, Hyalomma anatolicum anatolicum, Hyalomma dromedarii, Hyalomma impeltatum, Hyalomma marginatum rufipes, Hyalomma truncatum, Rhipicephalus evertsi evertsi, Rhipicephalus sanguineus group and Rhipicephalus simus simus. Major ecological changes have occurred due to extensive animal movement, deforestation, desertification and establishment of large mechanized agricultural schemes. These factors have certainly affected the distribution of ticks and tick-borne diseases in the Sudan. The absence of $A$. variegatum and $A$. lepidum in northern Sudan was not surprising, since these tick species are known to survive in humid areas and not in the desert and semi-desert areas of northern Sudan. The absence of $B$. annulatus in northern and central Sudan is in accordance with the finding that this tick species is restricted to the southern parts of the central Sudan. The presence of $\mathrm{H}$. anatolicum anatolicum in Um Benin in relatively high abundance is an interesting finding. The present finding may indicate that the southern limit of this species has changed and moved southwards to latitude $13^{\circ} \mathrm{N}$. It is concluded that major changes in tick distribution have taken place in the Sudan.

Keywords: Cattle, preliminary survey, Sudan, ticks
\end{abstract}

\section{INTRODUCTION}

Eleven genera of ticks and 63 tick species infesting a variety of animal species, including birds and rep-

* Author to whom correspondence is to be directed. E-mail: Diaeldin2000@hotmail.com

1 Central Veterinary Research Laboratories, Al Amarat, P.O. Box 8067, Khartoum, Sudan

2 Department of Parasitology, Faculty of Veterinary Medicine, University of Khartoum, P.O. Box 32 Khartoum North, Sudan

3 Utrecht University, Faculty of Veterinary Medicine, Division of Parasitology and Tropical Veterinary Medicine, P.O. Box 80165, 3508TD Utrecht, The Netherlands, and Department of Veterinary Tropical Diseases, Faculty of Veterinary Science, University of Pretoria, Onderstepoort, 0110 South Africa

Accepted for publication 11 June 2004-Editor tiles, have been identified in the Sudan (Hoogstraal 1956). According to Hoogstraal (1956), Karrar, Kaiser \& Hoogstraal (1963) and Osman, El Hussein, Neima \& Abdulla (1982) ticks infesting livestock in the Sudan are mainly Hyalomma anatolicum anatolicum, Hyalomma dromedarii, Hyalomma marginatum rufipes, Hyalomma impressum, Hyalomma impeltatum, Hyalomma truncatum, Rhipicephalus evertsi evertsi, Rhipicephalus sanguineus group, Rhipicephalus simus group, Rhipicephalus appendiculatus, Boophilus decoloratus, Boophilus annulatus, Amblyomma lepidum and Amblyomma variegatum.

Although different species of ticks and the diseases they transmit occur in different ecological regions of 
the world, their impact on animal production is similar in nature and importance (FAO 1984). Despite considerable progress made in combating ticks and tick-borne diseases, the latter seem to be increasing both in prevalence and severity. Tick-borne diseases are responsible for hundreds of million US dollar losses per year in tropical and temperate areas where they pose a problem. In the Sudan no accurate economic evaluations have been made. However, economic losses in Khartoum State alone due to tropical theileriosis have been estimated to be between 4 and 6 million US\$ (Latif 1994).

This cross-sectional survey was designed to provide additional data on the current distribution of major tick species associated with cattle in northern Sudan.

\section{MATERIALS AND METHODS}

\section{Study area}

The study area extended from the latitudes 11 $78^{\prime}-$ $19^{\circ} 61^{\prime} \mathrm{N}$ and longitudes $22^{\circ} 45^{\prime}-37^{\circ} 2^{\prime} \mathrm{E}$; this area is desert in the north and savannah in the south. Ticks were collected from cattle in Atbara and El Damer in the Northern Province and from Khartoum, Cen- tral Province. In the Blue Nile Province, the locations selected were Madani, Sennar, Um Benin and Damazin and in the White Nile Province, El Dieum, Rabak and Kosti. El obied, Nyala, Fasher and Genina represented the Western Province. From the Eastern Province localities in Gadarif, Kassala and Port Sudan were surveyed (Fig. 1).

\section{Collection of ticks}

At each location, ticks were collected from cattle on at least four farms that were kept separate. On each farm indigenous (Zebu) and cross (indigenous $x$ Friesian) bred animals were selected. The age groups of cattle on each farm sampled were: those less than 1 year, 1-2 years, 2-3 years, 3-4 years and more than 4 years. Cattle sampled were of different sexes and they were maintained under three managemental systems: intensive (zero grazing), extensive (out-grazing) and semi-intensive.

Total body collections of ticks were made from cattle using a pair of blunt forceps. Prior to collection, each animal was cast and restrained. The ticks collected were kept separately according to body site in labelled universal bottles containing $70 \%$ ethanol. On each label geographical information was recorded indicating location, animal number, site of

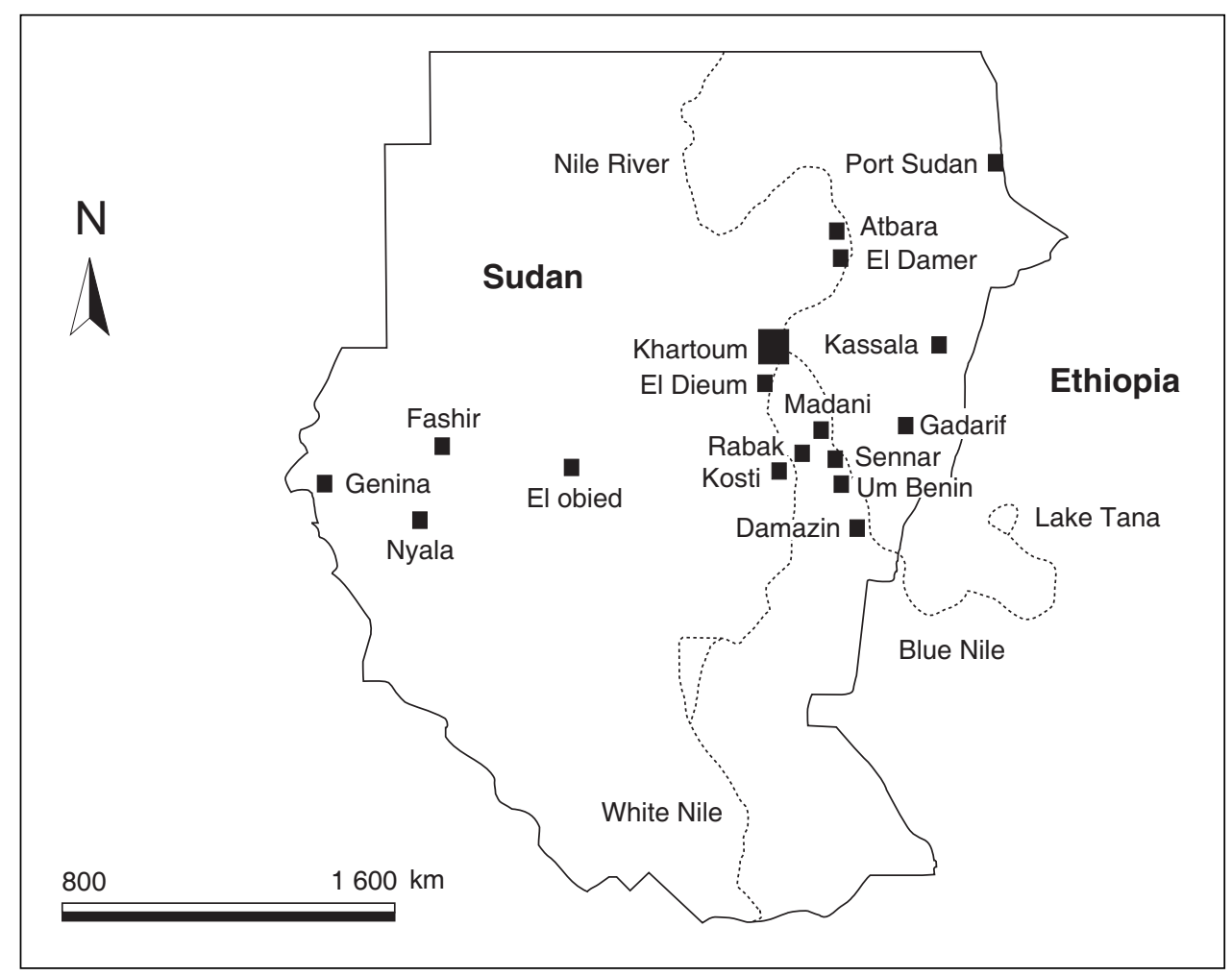

FIG. 1 Map of the Sudan showing localities where samples were collected 
the body and date of collection. In the laboratory the ticks were identified according to Hoogstraal (1956), Hoogstraal \& Kaiser (1959) and Okello-Onen, Hassan \& Essuman (1999).

\section{Statistical analysis}

Data collected on the ticks associated with cattle in the various localities were subjected to the appropriate general linear model (GLM) procedure of statistical analysis using the Statistical Analysis System (SAS) package. The SAS was used to perform analysis of variance (ANOVA) while mean separations were performed using the Ryan-Einot-GabrielWelsch (REGW) multiple range test (Day \& Quinn 1989).

\section{RESULTS}

Four genera and 11 species of ticks were identified during the survey period. The tick species were $A$. lepidum, $A$. variegatum, $B$. decoloratus, $H$. anatolicum anatolicum, $H$. dromedarii, $H$. impeltatum, $H$. marginatum rufipes, $H$. truncatum, $R$. evertsi evertsi, $R$. sanguineus group and $R$. simus simus. Most of the ticks were found in the upper perineum (i.e. from the base of tail, around the anus and around the vulva of female animals).

The ANOVA, mean squares, R-squares, coefficient of variance and $F$ values are shown in Table 1. In general, the mean number of ticks per head of cattle was relatively low, ranging from $(5.8 \pm 0.63)$ in Port Sudan to (19.6 \pm 2.25$)$ in Khartoum (Table 2). With the exception of Boophilus spp., males outnumbered females of all tick species. There were no significant differences $(P>0.05)$ between mean number of ticks per head of cattle in the zero grazing, out-grazing and semi-intensive systems. Data on distribution, highest and lowest mean, and abundance are given separately for each species as follows:

\section{Amblyomma lepidum}

This East African bont tick species was found in all locations, with the exception of Atbara, El Damer and Khartoum and Um Benin. It was recorded along the White Nile from El Dieum to Rabak. In Western Province this tick species was prevalent in all locations, while in Eastern Province it was recorded in Gadarif and Port Sudan, but not in Kassala.

The highest mean total body collection of ticks was recorded in Gadarif $(3.3 \pm 0.87)$, while the lowest mean was recorded in El Dieum (0.4 \pm 0.22 )(Table
2). There was a significant difference $(P<0.05)$ between the mean number of ticks collected in Gadarif, Madani, El obied and Damazin in comparison with other locations. But there were no significant differences $(P>0.05)$ between the numbers of ticks collected in Madani, El obied and Damazin (Table 2).

\section{Amblyomma variegatum}

The tropical bont tick was only found in Kosti, El obied and Nyala. The highest mean total body count of ticks was recorded in El obied (1.2 \pm 0.42$)$, while the lowest mean was recorded in Nyala $(0.5 \pm 0.22)$ (Table 2). There was a significant difference $(P<$ $0.05)$ in the mean total body count of ticks in El obied in comparison with Nyala and Kosti, while there was no significant difference $(P>0.05)$ between the counts in Nyala and Kosti (Table 2).

\section{Boophilus decoloratus}

The blue tick was only recorded in Madani and Rabak. There was no significant difference $(P>0.05)$ between the mean total body count of ticks in Madani (1.6 \pm 0.311$)$ and in Rabak (1.5 $\pm 0.0 .34)$ (Table 2).

\section{Hyalomma anatolicum anatolicum}

This xerophilic tick was the most abundant species in Atbara, El Damer and Khartoum. In Port Sudan it was only collected from a single host. The highest mean was recorded in Khartoum (6.6 \pm 1.17$)$ while the lowest mean was in Port Sudan $(1.1 \pm 0.28)$ (Table 2). There was a significant difference $(P<$ 0.05 ) between the mean total body count of ticks in Khartoum in comparison with other locations. However, there was no significant difference $(P>$ $0.05)$ between the mean number of ticks collected from Khartoum compared to Atbara, El Damer and Madani (Table 2). There was also no significant difference $(P>0.05)$ between the mean numbers of ticks collected in Sennar, Um Benin, Kosti and Kassala (Table 2).

\section{Hyalomma dromedarii}

The camel tick was collected in all locations with the exception of Kosti and Kassala. The highest mean total body count of ticks was recorded in El Damer $(3.6 \pm 0.97)$, while the lowest mean was recorded in Damazin and Fasher $(0.5 \pm 0.22)$ (Table 2). There was a significant difference $(P<0.05)$ between the mean numbers of ticks collected in El Damer in comparison with other locations. On the other hand, 

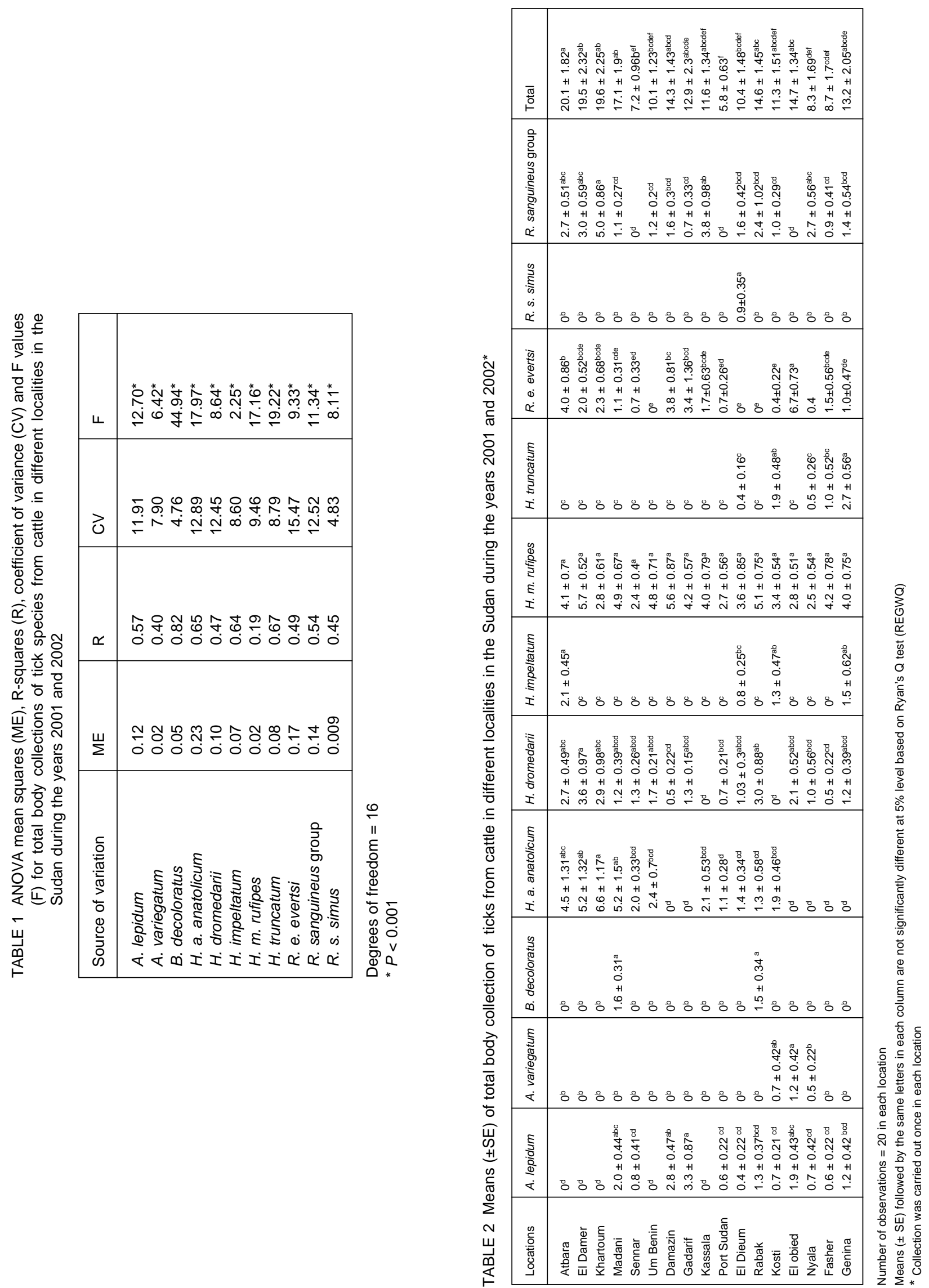
there was a significant difference $(P<0.05)$ in the mean numbers of tick collected in Damazin and Fasher and the rest of the locations (Table 2).

\section{Hyalomma impeltatum}

Kratz's Hyalomma was recorded in Atbara with the highest mean numbers of ticks $(2.1 \pm 0.45)$, while the lowest mean recorded in El Dieum $(0.8 \pm 0.25)$ (Table 2). There was a significant difference $(P<$ $0.05)$ in the mean number of ticks collected in Atbara in comparison with other locations. There was no significant difference $(P>0.05)$, however, between the numbers of ticks collected in Atbara, Genina and Kosti; which were significantly different $(P<$ 0.05) from those in El Dieum (Table 2).

\section{Hyalomma marginatum rufipes}

The hairy Hyalomma tick was found in all locations. The highest mean total of these ticks was recorded in El Damer $(5.7 \pm 0.52)$, with the lowest mean in Sennar $(2.4 \pm 0.4)$ (Table 2). There were no significant differences $(P>0.05)$ in the mean numbers of ticks collected from all locations (Table 2 ).

\section{Hyalomma truncatum}

The highest mean number of ticks of this species was recorded in Genina ( $2.7 \pm 0.56)$, while the lowest mean was recorded in El Dieum $(0.4 \pm 0.16)$ (Table 2). This species was not recorded in Northern, Central and Blue Nile Provinces. The presence of this tick species was significantly different $(P<$ $0.05)$ in Genina in comparison with other locations. There were no significant differences $(P>0.05)$ between the mean numbers of ticks collected in $\mathrm{El}$ Dieum, Nyala and Fasher (Table 2).

\section{Rhipicephalus evertsi evertsi}

The red-legged tick was present in all locations with the exception of Um Benin, El Dieum and Rabak. The highest mean total body count of ticks was recorded in El obied $(6.7 \pm 0.73)$, while the lowest mean was recorded in Kosti and Nyala $(0.4 \pm 0.22)$ (Table 2). There was a significant difference $(P<$ 0.05 ) in the mean number of ticks collected in El obied in comparison with other locations. There were, however, no significant differences in numbers $(P>0.05)$ between those collected in $\mathrm{El}$ Damer, Khartoum, Kassala and Fasher (Table 2).

\section{Rhipicephalus sanguineus group}

This tick species was not recorded in El obied, Port Sudan and Sennar locations, but it was present in the other locations (Table 2). The highest mean total body counts were recorded in Khartoum (5.0 \pm $0.86)$, while the lowest was recorded in Gadarif $(0.7$ \pm 0.33 ). The presence of this tick species was significantly different $(P>0.05)$ in Khartoum in comparison with other locations. There were no significant differences $(P>0.05)$ between Madani, Um Benin, Damazin, Rabak, Kosti, Fasher and Genina (Table 2).

\section{Rhipicephalus simus simus}

This tick species was recorded only in El Dieum where the mean number of ticks collected was 0.9 \pm 0.35 (Table 2).

\section{DISCUSSION}

Since the previous surveys on ticks in the Sudan conducted by Hoogstraal (1956), Karrar et al. (1963), Osman, Ibrahim \& Osman (1977) Osman et al. (1982), FAO (1983) and Jongejan, Zivkovic, Pegram, Tatchell, Fison, Latif \& Paine (1987), major ecological changes have occurred due to extensive animal movement, deforestation, desertification and the establishment of large mechanized agricultural schemes (Hassan \& Osman 2003). These factors have certainly affected the distribution of ticks and tick-borne diseases in the Sudan. As a result knowledge on tick-borne disease prevalence throughout the Sudan is fragmented (El Hussein, Mohammed, Osman \& Osman 1991; El-Imam 2003). This crosssectional survey was designed to provide a further understanding of the current distribution of the major ticks species in the Sudan.

From the knowledge of the distribution of tick vectors at a given location, the potential distribution of diseases they transmit can be broadly predicted (FAO 1984). The prevalence of the 11 tick species (Table 2) recorded during this study is an indication of the prevalence of the most important tick-borne diseases (TBDs) in the Sudan. Although studies on TBDs were not carried out in this study, the possibility of their presence cannot be ruled out since the most potential tick vectors transmitting other TBDs were reported in the Sudan in 1983 (FAO 1983).

The tick species identified in this survey are generally similar to those reported by Hoogstraal (1956), Karrar et al. (1963), FAO (1983), Jongejan et al. (1987) and El-Imam (2003). The absence of $A$. variegatum and $A$. lepidum in northern Sudan is not surprising, since these tick species are known to survive in humid areas (Jongejan et al. 1987; Os- 
man \& Hassan 2003) but not in desert and semidesert areas such as northern Sudan (Hoogstraal 1956). It is not surprising that the presence of $A$. lepidum in Gadarif represented the highest mean total body collection among the locations that were investigated, as the area is known to be favourable for the propagation of this tick species (Karrar et al. 1963). Although this tick species has not previously been reported from El Dieum, a low level of infestation was recorded during this investigation. Movement of tick-infested cattle from Kordofan and the Upper Nile State, where this tick species occurs (Hoogstraal 1956) as well as migrating birds may have introduced this species into El Dieum (Hoogstraal 1961). The same interpretation may apply to Port Sudan, where A. lepidum was recorded on one indigenous domestic bovine introduced from Halfa El Gadida, where A. lepidum is prevalent (Karrar et al. 1963). No $A$. variegatum was encountered on cattle during the period of the present investigation in Kassala. This may be attributed to the seasonal activity of this tick species, as this survey was conducted in April in the Kassala area. Osman et al. (1982) reported that $A$. lepidum reached peak activity between August and December in the rainy season in Kordofan. Moreover, attempts by the local farmers to control ticks by the indiscriminate use of acaricides may have caused fluctuations in tick populations (FAO 1984).

The absence of $B$. annulatus in northern and central Sudan is in accordance with the finding that this tick species is restricted to the southern parts of central Sudan (FAO 1983). Only small numbers of $B$. decoloratus ticks were recorded during this study in Madani and Rabak (Table 2). The presence of $H$. a. anatolicum in Northern and Central Provinces implies that $T$. annulata is likely to be endemic in these areas (El Ghali \& El Hussein 1995; Elhaj \& Hamid 2003). This tick species has the ability to establish itself in animal housing in order to complete its life cycle (FAO 1984). All the animals surveyed in Atbara, El Damer and Khartoum were kept under an intensive managemental system (closed system) in which sheds are constructed of local building materials. Sites such as mud walls with cracks, and water and food containers could be used by ticks as shelters, which allow them to survive adverse environmental conditions. The presence of $H$. a. anatolicum in Um Benin in relatively high abundance (2.4 \pm 0.7$)$ (Table 2) is an interesting finding. According to the publication of the FAO (1983) only one female of this tick species was collected from Um Benin. In the present survey, greater numbers of ticks of both sexes were encountered.
This finding may indicate that the limit of this tick species has moved southwards to latitude $13^{\circ} \mathrm{N}$. This may be attributed to ecological and other changes that have occurred since 1983 as a result of drought, animal movements, deforestation, desertification and establishment of large irrigation schemes. However, this finding needs to be verified by conducting an intensive survey, which includes all the seasons of the year. The low level of $H$. dromedarii recorded in this study in the Khartoum area may be a reflection of the fact that cattle do not frequently come in contact with camels in this area, since $H$. dromedarii is well known as a camel tick (Hoogstraal 1956).

Rhipicephalus e. evertsi and the $R$. sanguineus group, though present in most of the locations investigated, are unlikely to play a significant role in the epidemiology of tropical theileriosis. In previous studies in the Sudan, large numbers of $R$. sanguineus have been reported on livestock in Darfour Province (Osman 1978) and in Kassala Province (Karrar et al. 1963). Balfour in 1911 (cited by Hoogstraal 1956) mentioned that $R$. e. evertsi was introduced into the Khartoum area on cattle from Malakal in southern Sudan. This tick species and R. sanguineus were found to infest sheep, goats, dogs, birds, horses and donkeys (Hoogstraal 1956). Both tick species are now established in Khartoum (Kheir \& Majid 1999).

The population density of the species identified was variable in the locations in which the survey was conducted (Table 2). The highest tick count per animal was encountered in Khartoum (19.6 \pm 2.25$)$, while the lowest tick count was recorded in Port Sudan (5.8 \pm 0.63 ) (Table 2). These differences may be attributed to the managemental systems, host density, vegetation cover and other ecological factors. The greater number of ticks in Khartoum than in other locations is probably due to the dense livestock population in the area, which would have led to a high pick-up rate of ticks by cattle that are always kept in pens. Cattle in the other locations are not confined in pens because of the nomadic life of cattle owners. The lower infestation rates in Western Province may be attributed to the nature of the grazing pastures, which are relatively open and dry with little vegetation cover. The nomadic system of livestock production in western Sudan enhances control of tick populations as grazing areas are naturally spelt (Jongejan et al. 1987).

The minority of the tick species (four out of the 11) (Table 2) was present in nearly all locations. However, the occurrence of certain species was very 
D.A. SALIH et al.

high in some areas and very low in others. For example, $A$. lepidum, which is the most dominant species in Damazin (Table 2), was less prevalent in Fasher. This may be attributed to the type of animal husbandry practical and a favourable humid environment in areas around the Blue Nile River. Similarly, the highest mean number of $H$. impeltatum was recorded in Atbara and the lowest mean number in El Dieum (Table 2). This tick is mainly restricted to the dry zone and its immature stages are commonly associated with desert rodents (Hoogstraal 1956).

The absence of any tick species in any given period does not mean that it is absent from an area, as it can reappear when optimum climatic conditions prevail (Osman et al. 1982). Furthermore, the distribution limits of ticks are not always constant and are determined by a complicated interplay of factors such as climate, vegetation cover, host density, host susceptibility, host resistance, grazing habits and types of animal husbandry (Tatchell \& Easton 1986; Punyua, Latif, Nokoe \& Capstick 1991; Sonenshine \& Mather 1994).

The overall infestation rate of tick species in the present study was much lower than was expected if it is compared with the findings of Jongejan et al. (1987). Certain environmental and managemental factors might have been responsible for the lower tick burdens. These include the high ambient temperatures and low relative humidities, which prevailed during the period of the study, which may have affected the breeding abilities of the ticks. Application of chemical acaricides as sprays or hand dressings was practised in some locations, and despite its occasional and improper use, it still gives a degree of control of ticks on the cattle.

The introduction of hens as a means of biological control (Hassan, Dipeolu, Amoo \& Odhiambo 1991; Hassan, Dipeolu \& Munyinyi 1992), as practised in many locations, might also have resulted in reduced tick numbers. Another factor that could contribute to a low level of ticks infestation, especially in a closed system (zero grazing), is the regular removal of dung, and free-living stages of ticks are collected and burnt along with the litter.

In conclusion, it must be emphasized that this is an ad hoc survey, aimed at determining the tick species associated with cattle in the Sudan. In order to re-map tick prevalence and distribution as reported by Hoogstraal (1956), a large scale and systematic survey which includes ticks on all livestock and wildlife species in the country should be conducted.

\section{ACKNOWLEDGEMENTS}

This research was partially supported by the International Atomic Energy Agency (IAEA) through project no. SUD/05/027 entitled "Control of ticks and Tick-borne Diseases". This work is published with the kind permission of the Director-General, Animal Resources Research Corporation.

\section{REFERENCES}

DAY, R.W. \& QUINN, G.P. 1989. Comparison of treatment after an analysis of variance in ecology. Ecological Monographs, 59:433-463.

EL GHALI, A.A. \& EL HUSSEIN, A.M. 1995. Diseases of livestock in El Damer Province, El Nile State, Sudan: A two-year retrospective study. Sudan Journal of Veterinary Science and Animal Husbandry, 34:37-45.

EI HUSSEIN, A.M., MOHAMMED, S.A., OSMAN, A.K. \& OSMAN, O.M. 1991. A preliminary survey of blood parasites and brucellosis in dairy cattle in Northern State. Sudan Journal of Veterinary Research, 10:51-56.

ELHAJ, M.T. \& HAMID, M.E. 2003. Haematological and serum chemistry studies on crossbred calves infected with Theileria species. Sudan Journal of Veterinary Science and Animal Husbandry, 42:128-140.

El-IMAM, A.H. 2003. Ecological studies on ticks (Acari: Ixodidae) infesting cattle in Kosti province. Sudan Journal of Veterinary Science and Animal Husbandry, 42:62-71.

FAO. 1983. Ticks and tick-borne diseases control. The Sudan: tick ecology and tick control, Technical report No. 1, AG: CP/SUD/024/DEN, Rome: Food and Agricultural Organization of the United Nations.

FAO. 1984. Tick and tick-borne diseases control. A practical field manual. Vol. I and II. Rome: Food and Agricultural Organization of the United Nations.

HASSAN, S.M. \& OSMAN, A.M. 2003. Ecological and biological factors determining population dynamics of ixodid ticks: A review. Sudan Journal of Veterinary Science and Animal Husbandry, 42:16-44.

HASSAN, S.M., DIPEOLU, O.O. \& MUNYINYI, D.M. 1992. Influence of exposure period and management methods on the effectiveness of chickens as predators of ticks infesting cattle. Veterinary Parasitology, 43:301-309.

HASSAN, S.M., DIPEOLU, O.O., AMOO, A.O. \& ODHIAMBO, T.R. 1991. Predation on livestock ticks by chicken. Veterinary Parasitology, 38:199-204.

HOOGSTRAAL, H. 1956. African Ixodoidea. I. Ticks of the Sudan (with special reference to Equatoria Province and with preliminary reviews of the genera Boophilus, Margaropus, and Hyalomma). Department of the Navy, Bureau of Medicine and Surgery. Washington, D.C., USA.

HOOGSTRAAL, H. \& KAISER, M.N. 1959. Observations on Egyptian Hyalomma ticks (Ixodoidea: Ixodidae). 5: Biological notes and differences in identity of $H$. anatolicum and its subspecies anatolicum Koch and excavatum Koch among Russian and other workers identity of $H$. lusitanicum Koch. Entomological Society of America, 52:243-261.

HOOGSTRAAL, H. 1961. Migrating birds and their ectoparasite in relation to disease. East Africa Medical Journal, 38:221226.

JONGEJAN, F., ZIVKOVIC, D., PEGRAM, R.G., TATCHELL, R.J., FISON, T., LATIF, A.A. \& PAINE, G. 1987. Ticks (Acari: Ixodidae) of the Blue and White Nile ecosystems in the 
Preliminary survey of ticks (Acari: Ixodidae) on cattle in northern Sudan

Sudan with particular reference to the Rhipicephalus sanguineus group. Experimental and Applied Acarology, 3:331-346.

KARRAR, G., KAISER, M.N. \& HOOGSTRAAL, H. 1963. Ecology and host-relationships of ticks (Ixodoidea) infesting domestic animals in Kassala Province, Sudan, with special reference to Amblyomma lepidum Donitz. Bulletin of Entomological Research, 54:509-522.

KHEIR, S.M. \& MAJID, A.A. 1999. Ticks, tsetse and biting flies of importance in Sudan: a review. Sudan Journal of Veterinary Science and Animal Husbandry, 38:137-142.

LATIF, A.A. 1994. Economic losses in exotic breeds of cattle due to theileriosis in the Sudan, in Tropical theileriosis in the Sudan, edited by A.M. Atelmanan \& S.M. Kheir. Proceedings of a workshop held at the Sudan Veterinary Association Residence, Khartoum, Sudan, 4-5 May, 1994.

OKELLO-ONEN, J., HASSAN, S.M. \& ESSUMAN, S. 1999. Taxonomy of African ticks: An identification manual. Nairobi, Kenya: ICIPE Science Press.

OSMAN, A.M. \& HASSAN, S.M. 2003. The ecology and distribution of the East Africa tick Amblyomma lepidum: A review. Sudan Journal of Veterinary Science and Animal Husbandry, 42:45-53.
OSMAN, O.M. 1978. Preliminary notes on the distribution of ticks (Acarina. Ixodidae) in Darfour Province, Sudan. Bulletin of Animal Health and Production in Africa, 26:329-333.

OSMAN, O.M., EL HUSSEIN, A.M., NEIMA, A. \& ABDULLA, H.S. 1982. Ecological studies on ticks (Acarina: Ixodidae) of Kordofan Region, Sudan. Bulletin of Animal Health and Production in Africa, 30:45-53.

OSMAN, O.M., IBRAHIM, A.M. \& OSMAN, A.G. 1977. Some observations on ticks of sedentary cattle in southern Darfour Province. Proceedings of the $8^{\text {th }}$ Veterinary Association Conference, Khartoum, Sudan: 82-92.

PUNYUA, D.K., LATIF, A.A., NOKOE, S. \& CAPSTICK, P.B. 1991. Tick (Acari: Ixodidae) infestations on Zebu cattle in western Kenya: seasonal dynamics of four species of ticks on traditionally managed cattle. Journal of Medical Entomology, 28:630-636.

SONENSHINE, D.E. \& MATHER, T.N. 1994. Ecological dynamics of tick-borne zoonoses. Oxford: Oxford University Press.

TATCHELL, R.J. \& EASTON, E. 1986. Tick (Acari: Ixodidae) ecological studies in Tanzania. Bulletin of Entomological Research, 76:229-246. 